\title{
KERAGAAN BERBAGAI VARIETAS BUNGA KOL DI LAHAN GAMBUT SANGAT DALAM PADA MUSIM KEMARAU
}

\author{
Muhammad Anang Firmansyah \\ Balai Pengkajian Teknologi Pertanian Kalimantan Tengah \\ Jl. G, Obos Km 5 Palangka Raya \\ e-mail : anang.firmansyah75@yahoo.com
}

\begin{abstract}
Abstrak
Lahan gambut tergolong lahan suboptimal yang memiliki kendala kemasaman yang tinggi, unsur meracun dan ketersediaan air. Lahan gambut saat musim hujan kelebihan air, sebaliknya saat musim kemarau kekurangan air. Tujuan penelitian ini untuk mengetahui varietas bunga kol yang adaptif dengan di lahan gambut sangat dalam $(7 \mathrm{~m})$ pada saat musim kemarau. Rancangan percobaan yang digunakan adalah Rancangan Acak Kelompok (RAK6x3). Perlakuan varietas bunga kol ada enam jenis, antara lain: PM 126 F1, Mona F1, Diamond F1, Bima 45 F1, Ilona F1, dan Snow White F1. Masing-masing perlakuan diulang sebanyak tiga kali. Hasil penelitian menunjukkan bahwa unsur N, P, K tanah gambut lokasi penelitian sangat tinggi sebagai akibat pengelolaan budidaya sayuran secara terus menerus. Parameter agronomis menunjukkan tidak ada perbedaan jumlah daun, namun berat brangkasan tertinggi diperoleh Bima $45 \mathrm{~F} 1$ sebesar $0,513 \mathrm{~kg} / \tan$ berbeda nyata dengan Ilona F1 $(0,233 \mathrm{~kg} / \tan )$ dan PM $126 \mathrm{~F} 1(0,289 \mathrm{~kg} / \mathrm{tan})$. Parameter produksi tidak terdapat beda nyata pada berat bunga kol, namun terdapat beda nyata pada diameter bunga kol. Parameter diamaeter bunga kol tertinggi diperoleh Bima $45 \mathrm{~F} 1(16,63 \mathrm{~cm})$ berbeda nyata dengan lainnya kecuali dengan Diamond F1 $(14,0 \mathrm{~cm})$. Pada parameter mutu maka terdapat perbedaan nyata kemanisan total, varietas Snow White F1 tertinggi tingkat kemanisannya mencapai $8,7^{\circ}$ Brix berbeda nyata dengan varietas lainnya, sedangkan kemanisan terendah diperoleh PM 126 F1sebesar 5,5 ${ }^{\circ}$ Brix.
\end{abstract}

Kata Kunci : Brassica oleraceae, lahan gambut, musim kemarau.

\begin{abstract}
Peatlands are classified as suboptimal land which has high acidity constraints, toxic elemens, and water availability. Peatland during the rainy season will have excess water, in contrast during the dry season lack of water. The purpose of this study was to determine the adaptive varieties of cauliflower in very deep peatlands $(7 \mathrm{~m})$ during the dry season. The experimental design used was a Randomized Block Design (RBD6x3). There are 6 types of cauliflowers, among others: PM 126 F1, Mona F1, Diamond F1, Bima 45 F1, Ilona F1, dan Snow White F1. Each treatment was repeated three times. The result showed that the element N, P, K of peat soils were very high as a result of the continuous management vegetable cultivation. Agronomic parameters showed no difference in the number of leaves, but the highest stover weight obtained by Bima F1 $0.513 \mathrm{~kg} /$ plant was significantly difference from Illona F1 (0.233 $\mathrm{kg} / \mathrm{plant})$ and PM $126 \mathrm{~F} 1(0.289 \mathrm{~kg} / \mathrm{plant})$. In the production parameters there is no significant difference in the weight of cauliflower, however there ia a real difference in the diameter of cauliflower. The higest diameter of cauliflower obtained by Bima $45 \mathrm{~F} 1(16.63 \mathrm{~cm})$ was
\end{abstract}


significantly difference from other varieties of cauliflower, except Diamond F1 $(14.0 \mathrm{~cm})$ varieties. In the quality parameter, there is a real difference in the total sweetness level, the highest White Snow F1 reaches $8.7^{\circ} \mathrm{Brix}$, it is significantly different from other varieties, while the lowest sweetness level is obtained by PM $126 \mathrm{~F} 1$ varieties of $5.5^{\circ} \mathrm{Brix}$.

Keywords : Brassica oleraceae, dry season, Peatlands,

\section{Pendahuluan}

Bunga kol merupakan salah satu jenis sayuran yang memiliki nilai ekonomis tinggi. Budidaya tanaman bunga kol masih sangat jarang, karena belum banyak petani yang mempunyai teknologi penanamannya di lapang.

Bunga kol mampu tumbuh baik di tanah mineral dataran rendah di Kalimantan Tengah, namun demikian untuk di lahan gambut belum banyak diuji coba. Hal ini terkait tanah gambut yang memiliki kendala cukup besar, yakni kemasaman tanahnya yang tinggi, kelembaban tanahnya tinggi, bahkan rentan terhadap genangan. Sedangkan pada musim kemarau rawan terhadap kekeringan dan kebakaran.

Pengelolaan unsur hara yang seimbang yang diperlukan tanaman dan unsur hara yang tersedia, merupakan tujuan untuk mengoptimalkan produksi bunga kol dan meminimalkan kontaminasi air tanah akibat unsur hara yang berlebihan, selain itu meningkatkan produktivitas tanah (Zvalo and Respondek, 2007).

Suhu optimal untuk pertumbuhan dan perkembangan bunga kol antara 18$20^{\circ} \mathrm{C}$ selama siang hari. Pada suhu siang hari di atas $27^{\circ} \mathrm{C}$ maka bunga kol akan cenderung memiliki daun penutup mahkota bunga yang kecil, mahkota bunga kecil, berwarna kekuningan seperti sinar matahari (Koike et al. 2009). Sifat tanah terutama kedalaman muka air tanah mempengaruhi perpanjangan perakaran bunga kol. Kristensen and Boogaard (1998) menyatakan bahwa perakaran bunga kol mampu memanjang 1 $\mathrm{mm} / \mathrm{hari} / 1^{\circ} \mathrm{C}$ selama periode pertumbuhan dan mencapai mendekati $100 \mathrm{~cm}$ pada akhir pertumbuhan. Firmansyah et al. (2013) menyatakan bahwa pada tanah yang memiliki drainase buruk atau muka air tanah dangkal maka perpanjangan akar bunga kol dibatasi sampai kedalaman muka air tanah saja.

Pemupukan pada tanaman bunga kol mampu meningkatkan produksi Pemupukan $N$ dan $S \quad(250: 60 \mathrm{~kg} / \mathrm{ha})$ mampu meningkatkan produksi sebesar 
26,6\% dibandingkan kontrol (Cekey et al., 2011)

Produksi bunga kol di Nova Scotia rata-rata mencapai $0,710 \mathrm{~kg}$ per mahkota, jika dikonversi dengan populasi di Indonesia sebanyak 24.800 tanaman/ha maka mencapai 17,6 t/ha. Serapan $N$ total bunga kol antara 8-10 g/tanaman, semakin tinggi serapan $\mathrm{N}$ oleh tanaman maka produksi semakin meningkat $\mathrm{Yc}=176,2$ Pnuptake $-804,3, \mathrm{R} 2=0.64^{* *}$ (Li et al., 2009). Rata rata produksi bunga kol di California 21,2-22,2 tha (Koike et al., 2009), sedangkan poduksi bunga kol dengan penambahan $\mathrm{N}$ sebanyak 252,5 $\mathrm{kg} / \mathrm{ha}$ di Sao Paulo mencapai 13,47 t/ha (Oliviera et al., 2017). Produksi bunga kol di Nepal dengan berbagai perlakuan Nitrogen dan pupuk kandang berkisar atara 125,4 - 658,68 atau setara dengan 3,1116,34 t/ha (Basyal, 2011)

Tujuan penelitian ini adalah untuk melihat sejauh mana jenis bunga kol yang mampu beradaptasi di lahan gambut sangat dalam pada saat musim kemarau.

\section{Metodologi}

Penelitian dilakukan di musim kemarau bulan Juli hingga September 2017. Lokasi penelitian di Bumi Ayu, Kecamatan Mentawa Baru Ketapang,
Kabupaten Kotawaringin Timur, Provinsi Kalimantan Tengah.

Penelitian dilakukan di lahan petani dengan jenis tanah gambut sangat dalam (7 m). Rancangan percobaan menggunakan Rancangan Acak Kelompok terdiri dari enam perlakuan dan diulang tiga kali (RAK 6x3). Perlakuan tersebut antara lain: $\mathrm{V} 1=\mathrm{PM} 126 \mathrm{~F} 1, \mathrm{~V} 2=$ Mona F1, V3 = Diamond F1, V4 = Bima $45 \mathrm{~F} 1, \mathrm{~V} 5=$ Ilona F1, V6 = Snow White F1.

Satuan percobaan berukuran 1 × 3 m dengan jarak tanam $60 \times 30 \mathrm{~cm}$ sistim baris ganda. Penanaman menggunakan plastik hitam perak, yang diberi lobang diameter $20 \mathrm{~cm}$ untuk tempat penanaman.

Pupuk dasar digunakan dolomit sebanyak 3 t/ha, pupuk kandang sebanyak 5 t/ha, SP36 $150 \mathrm{~kg} / \mathrm{ha}$, NPK 16:16:16 250 $\mathrm{kg} / \mathrm{ha}$. Pupuk susulan digunakan sistem kocor, melarutkan $3 \mathrm{~kg}$ NPK dalam air 200 liter, dan diberikan setiap minggu sekali sebanyak $220 \mathrm{ml}$ per lubang. Penyiraman dilakukan setiap dua hari sekali jika tidak turun hujan. Penyiraman menggunakan air bor dan disiramkan menggunakan selang air.

Pengendalian OPT dilakukan secara rutin setiap minggu sekali menggunakan, Mankozeb, AzoksistrobinDifenokonazol, Metomil, kecuali Karbofuran diberikan saat tanam. 
Pengamatan parameter meliputi jumlah daun, berat brangkasan basah bagian atas, diameter bunga, berat bunga, tingkat kemanisan tangkai bunga, tingkat kemanisan bunga, dan tingkat kemanisan total bunga. Perbedaan nilai tengah antar perlakuan akan dianalisis dengan UJB Duncan taraf $5 \%$.

\section{HASIL DAN PEMBAHASAN}

\section{Karakteristik Iklim dan Tanah}

Curah hujan selama tahun 2017 mencapai $2.990,9 \mathrm{~mm} / \mathrm{th}$, dengan rata-rata bulanan $249,24 \mathrm{~mm} / \mathrm{bln}$. Pada bulan-bulan dimana kegiatan dilakukan yaitu bulan Juli, Agustus dan September tahun 2017, maka curah hujan masing-masing bulan tersebut sebesar 203, 92,5 dan $147 \mathrm{~mm} / \mathrm{bln}$ (Gambar 1)

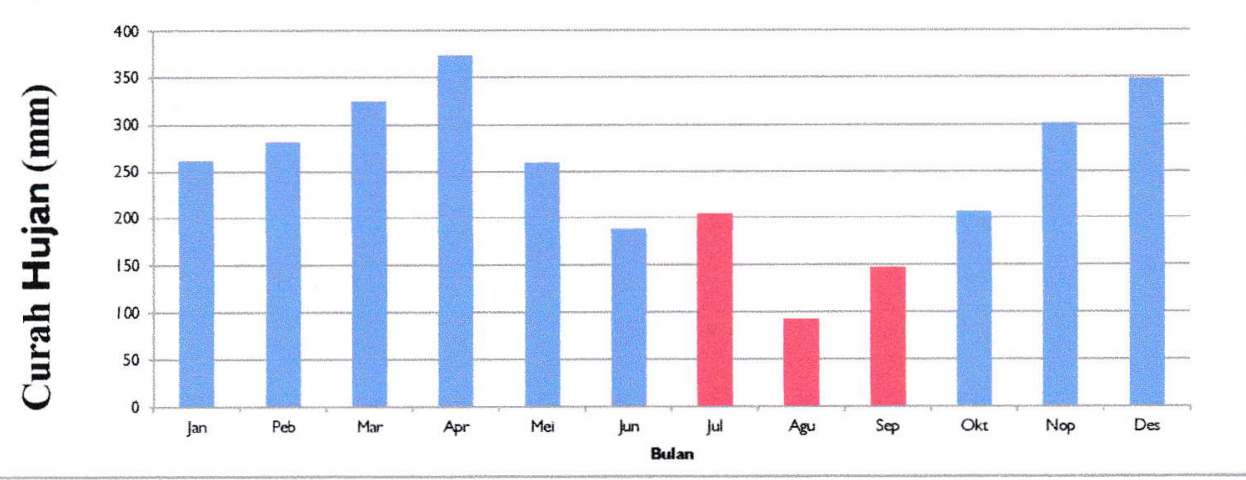

Gambar 1. Curah hujan di Kabupaten Kotawaringin Timur bulanan tahun 2017. (Sumber: BPS Kotim, 2017)

Suhu udara rata-rata tahun 2017 Juli, Agustus dan September berturut-turut adalah $26,77{ }^{\circ} \mathrm{C}$, sedangkan suhu udara $26,4,26,6,27,3{ }^{\circ} \mathrm{C}$ (Gambar 2 ). pada bulan-bulan dilakukan kegiatan yaitu

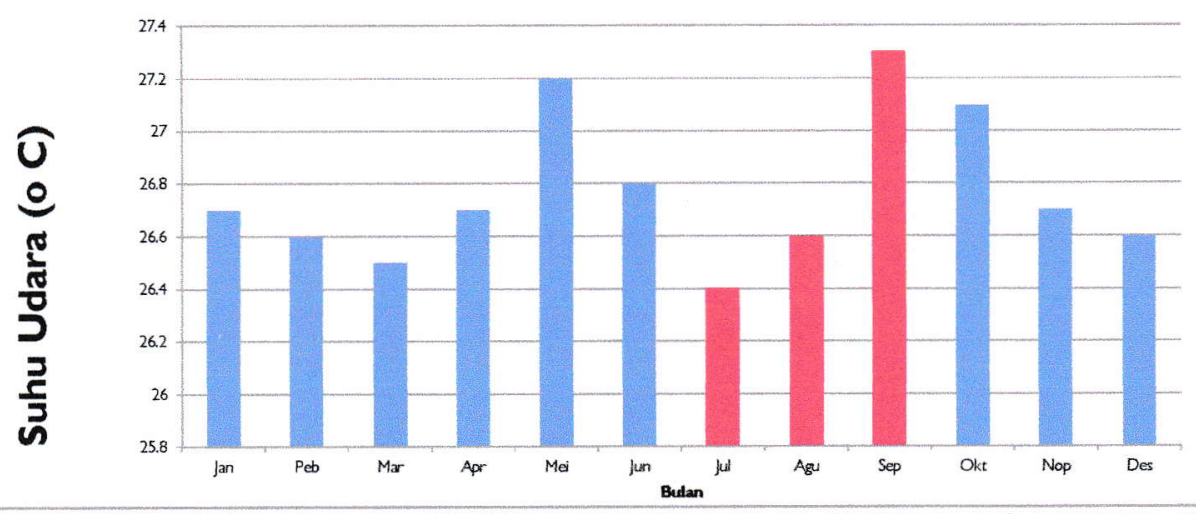

Gambar 2. Suhu Udara bulanan di Kabupaten Kotawaringin Timur tahun 2017. (Sumber: BPS Kotim, 2017) 
Tanah di lokasi kegiatan uji adaptasi berbagai varietas bunga kol merupakan bekas tanaman tomat dan telah lama diusahakan untuk tanaman sayuran. Tanah gambutnya sangat dalam, karena memiliki kedalaman lebih dari $3 \mathrm{~m}$.

Tanah gambut tergolong hemik, dengan muka air tanah sangat dangkal kurang dari $0,5 \mathrm{~m}$. Beberapa bagian masih terdapat tunggul-tunggul kayu yang sulit untuk dicabut sementara ini.

Karakteristik tanah sebelum dilakukan kegiatan diambil untuk dianalisa, kemudian setelah kegiatan juga dianalisa (Tabel 1).

Tabel 1. Karakteristik Tanah Gambut Awal dan Akhir Penelitian Kedalaman Tanah 0-20 cm di Kabupaten Kotawaringin Timur MK 2017

\begin{tabular}{|c|c|c|c|c|c|}
\hline \multirow{2}{*}{ Karakteris-tik Tanah } & \multirow{2}{*}{ Satuan } & \multicolumn{2}{|c|}{ Nilai } & \multicolumn{2}{|c|}{ Kriteria } \\
\hline & & Awal & Akhir & Awal & Akhir \\
\hline $\mathrm{pH} \mathrm{H} \mathrm{H}_{2} \mathrm{O}$ & - & 4,53 & 4,73 & M & M \\
\hline $\mathrm{pH} \mathrm{KCl}$ & - & 2,79 & 4,28 & - & - \\
\hline C-org & $\%$ & 56,33 & 52,04 & ST & ST \\
\hline N Total & $\%$ & 1,551 & 1,275 & ST & ST \\
\hline $\mathrm{C} / \mathrm{N}$ & $\%$ & 37,29 & 40,81 & ST & ST \\
\hline K-dd & $(\mathrm{cmol}(+) / \mathrm{kg})$ & 2,058 & 1,332 & ST & ST \\
\hline Na-dd & $(\mathrm{cmol}(+) / \mathrm{kg})$ & 1,167 & 1,034 & ST & ST \\
\hline Ca-dd & $(\mathrm{cmol}(+) / \mathrm{kg})$ & 28,293 & 36,505 & ST & ST \\
\hline Mg-dd & $(\mathrm{cmol}(+) / \mathrm{kg})$ & 7,398 & 7,578 & $\mathrm{~T}$ & $\mathrm{~T}$ \\
\hline KTK & $(\mathrm{cmol}(+) / \mathrm{kg})$ & 218,13 & 135,77 & ST & ST \\
\hline Kej. Basa & $\%$ & 17,84 & 34,21 & SR & $\mathrm{R}$ \\
\hline P-Bray 1 & ppm P & 213,4 & 287,51 & ST & ST \\
\hline P-Potensial & $\mathrm{mg} / 100 \mathrm{~g}$ & 19,87 & 69,32 & $\mathrm{R}$ & ST \\
\hline K-Potensial & $\mathrm{mg} / 100 \mathrm{~g}$ & 48,77 & 65,24 & $\mathrm{~T}$ & ST \\
\hline Kadar Abu & $\mathrm{mg} / 100 \mathrm{~g}$ & 2,88 & 10,08 & - & - \\
\hline
\end{tabular}

Hasilnya menunjukkan bahwa kemasaman tanah tidak berubah yaitu kategori masam dan $\mathrm{C}$ organik sangat tinggi. Beberapa karaktristik yang berubah cukup nyata adalah kejenuhan basa dari sangat rendah menjadi rendah, $\mathrm{P}$ Potensial dari rendah menjadi sangat tinggi, dan $\mathrm{K}$ Potensial dari tinggi menjadi sangat tinggi

Secara umum terlihat bahwa tanah di lokasi kegiatan telah mengalami pemberian pemupukan yang cukup intensif, baik pupuk organik maupun pupuk anorganik. Dimana data data karakteristik dari $\mathrm{N}$ total, $\mathrm{P}$ 
tersedia maupun basa dapat ditukar cukup tinggi.

\section{Pertumbuhan Tanaman}

Parameter agronomis berat brangkasan atas tertinggi diperoleh Bima 45 F1 sebesar $0,5130 \mathrm{~kg} / \operatorname{tanaman}$, dan berbeda nyata dengan PM 126 F1 maupun Ilona F1, dimana Ilona F1 memiliki berat brangkasan atas basah terendah mencapai 0,2325 $\mathrm{kg} /$ tanaman.

Pada parameter jumlah daun ratarata pertanaman antara 12,25 hingga 19,75 helai. Jumlah daun terbanyak pada varietas Snow White F1 yang tidak berbeda nyata dengan Bima 45 F1, Diamond F1, dan Mona $\mathrm{F} 1$, namun berbeda nyata dengan Ilona F1 dan PM 126 F1 (Tabel 2, Gambar 1).

Tabel 2. Parameter Brangkasan Atas Basah dan Jumlah Daun Beberapa Varietas Bunga Kol umur 46 HST di Lahan Gambut di Kabupaten Kotawaringin Timur MK 2017

\begin{tabular}{|l|l|ll|}
\hline \multicolumn{1}{|c|}{ Varietas } & $\begin{array}{c}\text { Berat Brangkasan } \\
\text { Atas Basah }(\mathrm{kg})\end{array}$ & Jumlah Daun \\
\hline PM 126 F1 & $0,2890 \mathrm{ab}$ & $12,25 \mathrm{a}$ \\
Mona F1 & $0,3910 \mathrm{abc}$ & $18,25 \mathrm{~b}$ \\
Diamond F1 & $0,4395 \mathrm{bc}$ & $18,50 \mathrm{~b}$ \\
Bima 45 F1 & $0,5130 \mathrm{c}$ & $19,50 \mathrm{~b}$ \\
Ilona F1 & $0,2325 \mathrm{a}$ & $14,50 \mathrm{a}$ \\
Snow White F1 & $0,4035 \mathrm{bc}$ & $19,75 \mathrm{~b}$ \\
\hline KK (\%) & 29,18 & 37,10 \\
\hline
\end{tabular}

Keterangan: Angka rata-rata yang diikuti oleh huruf yang sama tidak berbeda nyata menurut DMRT pada taraf nyata $5 \%$.

Kondisi parameter pertumbuhan ini menunjukkan bahwa masing-masing varietas memiliki spesifikasi tersendiri dan tergantung faktor genetiknya.

\section{Produksi Bunga Kol}

Bunga kol pada penelitian ini dipanen agak dini yaitu sekitar umr 46 HST, hal ini disebabkan adanya penampilan bunga kol yang mengalami serangan ulat daun yang cukup mengkhawatirkan. Beberapa varietas bunga kol menunjukkan fase sudah cukup matang dan beberapa varietas lainnya belum mencapai fase maksimal.

Pada parameter diameter bunga kol nampak bahwa varietas Bima 45 F1 terlebar mencapai $16,63 \mathrm{~cm}$ dan berbeda nyata dengan varietas lainnya kecuali dengan Diamond F1. Diameter bunga kol terendah ada pada varietas Mona F1 sebesar 9,5 cm (Tabel 3). 

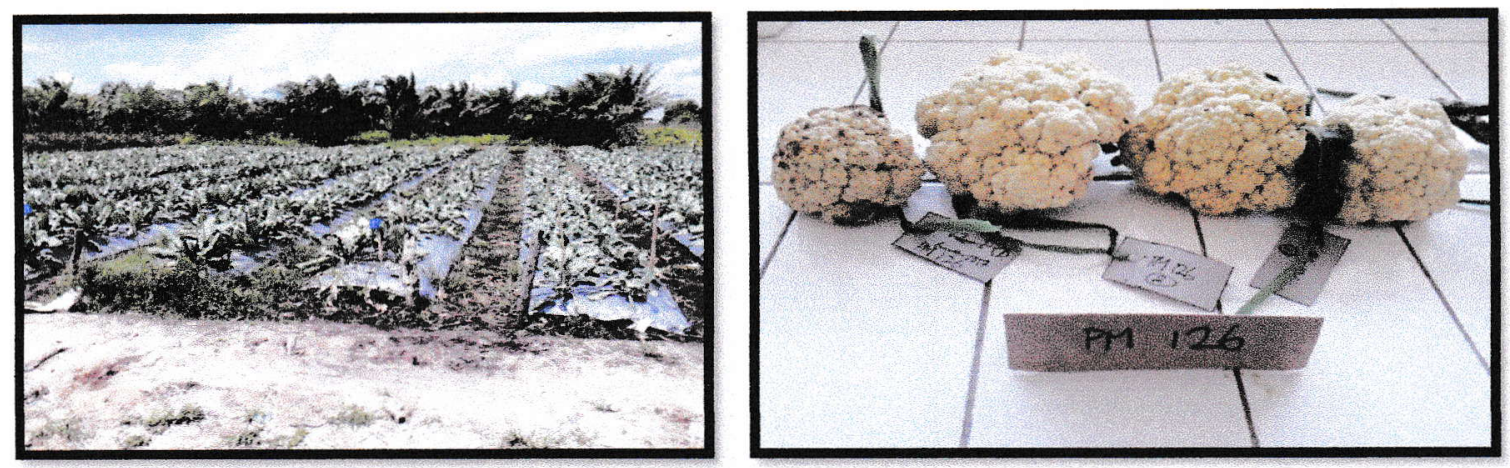

Gambar 3. Kondisi tanaman bunga kol di Gambar 4. Bunga kol varietas PM 126 F1. lahan gambut dalam menjelang panen di MT MK 2017.

Tabel 3. Parameter Diamater dan Berat Beberapa Varietas Bunga Kol umur 43 HST di Lahan Gambut Kabupaten Kotawaringin Timur MK 2017

\begin{tabular}{|l|r|r|}
\hline \multicolumn{1}{|c|}{ Varietas } & $\begin{array}{r}\text { Diameter Bunga Kol } \\
(\mathrm{cm})\end{array}$ & $\begin{array}{c}\text { Berat Bunga Kol } \\
(\mathrm{kg})\end{array}$ \\
\hline PM 126 F1 & $10,25 \mathrm{a}$ & $0,3280 \mathrm{a}$ \\
Mona F1 & $9,50 \mathrm{a}$ & $0,1263 \mathrm{a}$ \\
Diamond F1 & $14,00 \mathrm{abc}$ & $0,2140 \mathrm{a}$ \\
Bima 45 F1 & $16,63 \mathrm{c}$ & $0,2120 \mathrm{a}$ \\
Ilona F1 & $10,88 \mathrm{ab}$ & $0,1725 \mathrm{a}$ \\
Snow White F1 & $11,00 \mathrm{ab}$ & $0,1608 \mathrm{a}$ \\
\hline KK (\%) & 12,79 & 11,66 \\
\hline
\end{tabular}

Keterangan : Angka rata-rata yang diikuti oleh huruf yang sama tidak berbeda nyata menurut DMRT pada taraf nyata $5 \%$.

Parameter berat bunga kol nampak belum maksimal karena belum masak optimal pada beberapa varietas. Kisaran berat basah bunga kol yaitu 0,1608 $0,3280 \mathrm{~kg} /$ buah. Diantara varietas bunga kol yang dikaji maka tidak ada perbedaan nyata antar varietas. Penelitian Firmansyah et al. (2018) yang dilakukan pada musim hujan namun di tanah mineral memperoleh berat $0,397 \mathrm{~kg} /$ bunga $\mathrm{kol}$. Hal ini menunjukkan bahwa kondisi iklim dan jenis tanah, serta teknik budidaya memiliki pengaruh terhadap produksi bunga kol. Sehingga dapat diduga bahwa jenis tanah gambut memiliki potensi yang lebih rendah dibandingkan tanah mineral untuk memproduksi bunga kol. Berdasarkan hasil penelitian ini hanya varietas PM 126 yang masih mampu berproduksi tinggi, meskipun ditanam pada musim kemarau di tanah gambut sangat dalam.

Marliah et al (2013) varietas bunga kol PM 126 F1 memiliki keunggulan dengan produktivitas tinggi, varietas ini mampu menghasilkan bunga kol basah per tanaman sebesar $0,494 \mathrm{~kg}$ dan merupakan produksi lebih tinggi dibandingkan dua varietas bunga kol lainnya. Penelitian uji varietas ini menunjukkan bahwa PM 126 F1 di lahan gambut sangat dalam masih berpeluang untuk dikembangkan, karena produksinya cukup baik dibandingkan 
beberapa penelitian pada varietas yang sama di lahan mineral. Meriyanto et al. ( 2017) sebaliknya penanaman bunga kol PM 126 F1 di polybag juga memiliki keragaman produksi tinggi hanya 104,05 g/bunga kol. Penelitian Oktaviania dan Usmadia (2019) hanya mencapai produksi $270 \mathrm{~g}$ /bunga kol.

\section{Berdasarkan diameter bunga,} nampak bahwa PM 126 F1 memiliki bobot timbang lebih berat dibandingkan Bima 45 $\mathrm{F}$ 1, walaupun diameter bunganya lebih kecil. Hal ini penting pagi petani dan penjual, sebab bunga kol dijual berdasarkan berat, sehingga jika timbangannya mantap maka akan menguntungkan.

\section{Kualitas Produksi}

Kualitas bunga kol dapat ditinjau dari tingkat kemanisannya, sebab bunga kol yang memliki rasa manis akan lebih disukai oleh konsumen dibandingkan yang hambar.

Dari bagian bunga kol, maka umumnya mahkota bunga kol nampak lebih manis dibandingkan tangkai mahkota bunganya (Tabel 4).

Tabel 4. Parameter Mutu Beberapa Varietas Bunga Kol Umur 43 HST di Lahan Gambut di Kabupaten Kotawaringin Timur MK 2017

\begin{tabular}{|l|c|c|c|}
\hline \multicolumn{1}{|c|}{ Varietas } & $\begin{array}{c}\text { Kemanisan Tangkai } \\
\text { Mahkota }\left({ }^{\circ} \text { Brix }\right)\end{array}$ & $\begin{array}{r}\text { Kemanisan Mahkota } \\
\left({ }^{\circ} \text { Brix }\right)\end{array}$ & $\begin{array}{c}\text { Kemanisan Total } \\
\left({ }^{\circ} \text { Brix }\right)\end{array}$ \\
\hline PM 126 F1 & $4,60 \mathrm{a}$ & $6,45 \mathrm{a}$ & $5,525 \mathrm{a}$ \\
Mona F1 & $5,30 \mathrm{ab}$ & $7,05 \mathrm{ab}$ & $6,175 \mathrm{ab}$ \\
Diamond F1 & $4,80 \mathrm{a}$ & $6,95 \mathrm{ab}$ & $5,875 \mathrm{a}$ \\
Bima 45 F1 & $6,50 \mathrm{~cd}$ & $8,75 \mathrm{c}$ & $7,625 \mathrm{c}$ \\
Ilona F1 & $5,93 \mathrm{bc}$ & $7,95 \mathrm{bc}$ & $6,950 \mathrm{bc}$ \\
Snow White F1 & $7,25 \mathrm{~d}$ & $10,20 \mathrm{~d}$ & $8,725 \mathrm{~d}$ \\
\hline KK (\%) & 7,17 & 6,29 & 5,17 \\
\hline
\end{tabular}

Keterangan : Angka rata-rata yang diikuti oleh huruf yang sama tidak berbeda nyata menurut DMRT pada taraf nyata $5 \%$.

Tingkat kemanisan tangkai mahkota bunga kol tertinggi diperoleh varietas Snow White F1 mencapai 7,25 ${ }^{\circ}$ Brix, sedangkan mahkota bunga kol tertinggi diperoleh varietas Snow White F1 juga, 10,2 ${ }^{\circ}$ Brix. Kemanisan rata-rata tertinggi bunga kol pada varietas Snow White F1 8,725 ${ }^{\circ}$ Brix.

\section{KESIMPULAN}

Varietas bunga kol yang memiliki produksi tertinggi dan relative adaptif dengan lahan gambut sangat dalam adalah varietas PM $126 \mathrm{~F}$, sedangkan varietas bunga kol yang memiliki mutu terbaik dari segi kemanisannya adalah Snow White F1. 


\section{DAFTAR PUSTAKA}

Bashyal, L.N. 2011. Respone of cauliflower to Nitrogen fixing biofertilizerv and graded levels of Nitrogen. The Journal of Agriculture and Environment. 12(1):41-50. Diunduh 27 Oktober 2017.

https://www.nepjol.info/index.php / AEJ/article/.../6145.

BPS Kabupaten Kotawaringin Timur. 2017. Kotawaringin Timur dalam angka Tahun 2017.

Cekey, N., M. Slosar, A. Uher, Z. Balogh, M. Valskova, and T. Losak. 2011. The effect of nitrogen and sulphur fertilization on the yield and content of sulforaphan and nitrates in cauliflower. Acta Universitatis Agriculturae et Silviculturae Mendelianae Brynensis. 59(5):1722. Diunduh 27 Oktober 2017. https;//acta.mendelu.cz/media/pdf/a cta un_2011059050017.pdf

Firmansyah, M.A.,T.A. Atikah, and L. Lehar. The application of cattle bio-urine to the back sandy soils characteristics and cauliflowers (brassica oleraceae var. Botrytis) during rainy seasons BIOSCIENCE RESEARCH, 2018 15(3):2854-2859

Koike, S.T., M. Cahan, M. Cantwell, S. Fennimore, M. Lestrange, E. Natwick, R.F. Smith, and E. Takele. 2007. Cauliflower production in California. University of California. Division of Agriculture and Natural Resources. Publication 7219. Diunduh 27 Oktober 2017 www. anrcatalog.ucanr.edu/pdf/72 19.pdf.

Kristensen, K.T., and R. Boogaard. 1998 Temporal and spatial root development of cauliflower (Brassica oleracea L. var. botrytis L.). Plant and Soil 201: 37-47

Lie, H.,M R.J. Gordon, and R. Lada, 2009. Nitrogen assimilation ability of three cauliflower cultivar in relation to reduce Post Transplanting Nitrogen Supply. UC Davis, The Proceedings of the International Plant Nutrition Colloqium XVI. Diunduh 27 Oktober $2017 . \quad$ www. 
Escolarship.org/content/qt7752h5

sz/qt7752h5sz,df.

Marliah, A., Nurhayati, dan R. Riana.

2013. Pengaruh varietas dan konsentrasi pupuk majemuk terhadap pertumbuhan dan hasil tanaman kubis bunga (brassica oleracea 1.) J. Floratek 8: 118 - 126

Meriyanto, R. Hanan, dan H. Yanto. 2017. Respon pertumbuhan dan hasil tanaman kubis bunga (Brassica oleraceae var botrytis 1 . subvar pm $126 \mathrm{fl}$ ) akibat pemberian takaran pupuk kandang kotoran ayam di polybag pada dataran rendah. Jurnal Triagro. 2(2): 18-24.

Oktaviania, M. S. dan Usmadia. 2019. Pengaruh bio-slurry dan fosfor terhadap pertumbuhan dan hasil bunga kol (Brassica oleracea 1.) dataran rendah. Jurnal Bioindustri. 1(02): 125-137

Oliviera, FC., ACS. Almeida, LO Geisenhoff, Junior JAL, and AIS Niz. 2017. Effect of top dressing ntrogen levels on the productivity of cauliflower. Jabotical. 45(2):190-196. Diunduh 27
Oktober $2017 . \quad$ www Centifica.org.br/index.php/cientifi ca /article/viewFile/.../576.

Zval, V., and A. Respondek. 2009. Cauliflower, vegetable crops production gude for Nova Scotia. Perenia. Diunduh 27 Oktober 2017. www.perennia.ca/wpcontent/ploads/2015/12/cauliflowegude-2011.pdf, 